\title{
Strategic Analysis of Foreign Construction Enterprises in Chinese Construction Market
}

\author{
Husam Wahdan \\ (Master program, Faculty of Business and Management, Dong Hua University, Shanghai, China)
}

\begin{abstract}
The extensive opportunities in China's construction market attract many foreign construction enterprises, according to the National Bureau of Statistics of China 2013 foreign construction companies in this market does not exceed one percent of the total operating companies, this illustrates the amount of competition faced by these companies are very fierce, foreign construction enterprises to seize the opportunities in this market, it is important to understand how to develop effective strategies in order to meet the competitiveness, they must understand how adapt to China's legal, social, cultural, economic and technological environment along with changes brought about by competitors' advances and new needs of customers, they need to develop their capability to assess the opportunities, to secure their healthy growth, to survive, and achieving profits. This paper studied the current situation and the way of foreign construction enterprises to enter this market, the internal environment of Chinese construction market (PEST), and main types of foreign construction enterprise development strategy in this market, then find out the strengths in developing foreign firms businesses in this market, which these useful to understand the critical factors that are required to succeed, to develop strategic management guidelines for similar entities .
\end{abstract}

Keywords: Chinese Construction Market, Development Strategy, Foreign Construction Enterprises, PEST.

\section{Introduction}

Chinese construction market is one of the largest construction markets in the world, it is the largest construction market in Asia, this market has achieved record growth in the past ten years, it is expected to continue steady growth over the coming years as a result of increased economic growth, population growth, and encouragement from the government, after China's entry into the WTO has brought many opportunities for the construction industry, that led to increased foreign investment in the construction market due to improved legal and policy environment for foreign investment. These extensive opportunities in China's construction market attract many foreign construction firms, according to the National Bureau of Statistics of China [1] at the end of 2013 there were over 78000 construction enterprises work in China Among 699 foreign construction enterprises, it is clear that the amount of competition faced by these companies in the construction market of China is very fierce, foreign construction firms to seize the opportunities in this market, it is important to understand how to develop effective strategies in order to meet the competitiveness and dynamic change in this market, understand type of product or service to be provided, and recruit, develop and retain the right people for running the business in China, Moreover they must understand how adapt to China's legal, social, cultural, economic and technological environment along with changes brought about by competitors' advances and new needs of customers, they need to develop their capability to assess the opportunities, analyze the risks, and make informed decisions concerning market entry mode and strategies best prepared for future construction business, to secure their healthy growth, to survive, and achieving profits.

Based on the description above, the purpose of the study are to understand How good are foreign construction enterprises to implement strategies management in this market, Opportunities for foreign construction business operating in China and, How do foreign construction enterprises respond to the environment and competitive situation, what is the source of competitive advantage for foreign construction enterprises, which these will be used to develop strategic management guidelines for similar entities .

\section{The Current Situation Of}

\section{The Foreign Construction Enterprises In China}

According to the National Bureau of Statistics of China 2013, at the end of 2012 there were over 680 foreign construction enterprises work in China, among 385 funded from Hongkong, Tiwan, Macao, employing over 232500 employers : 


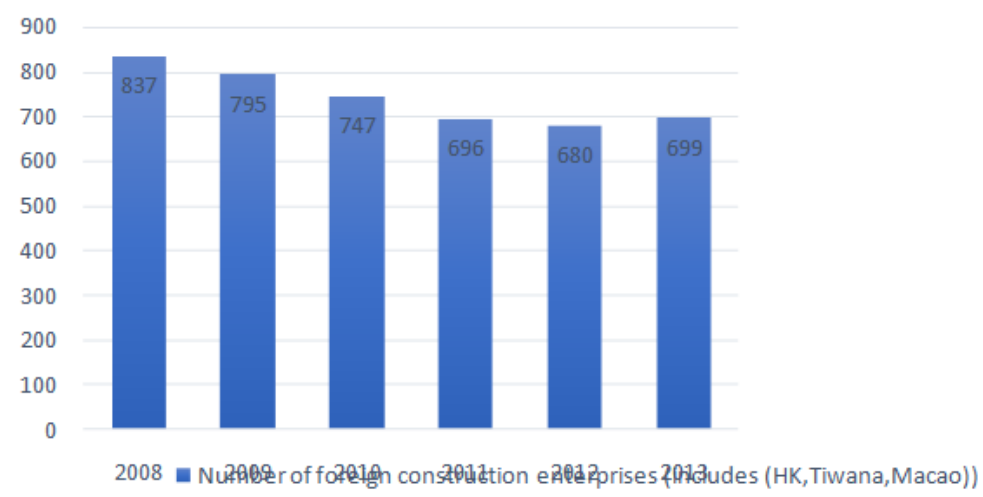

Figure 1: Number of foreign construction firms (2008-2013) (National Bureau of Statistics of China)

Foreign investors and contractors now have much broader access to the Chinese construction market than before, and many private and foreign constructors are rapidly developing in Chinese certain provinces, special economic zones that have been initiated to attract foreign investment, where the net overseas direct investment in construction sector in 2012 was 1830.3 million RMB[2], and the overseas direct investment stock reached 6682.12 million, the following are some examples of Foreign Investment Projects in China, Anhui comprehensive traffic infrastructure project, New rural construction in Huangshan, industrial base infrastructure construction in Xuancheng, Second and third phase of City environment improvement project in Wuhan, Magna manufacturing center in Tianjin ,Bridgestone added investment in Tianjin , GM technique research institute in Shanghai, TOYOTA auto study institute, in Changshu, Jiangsu .

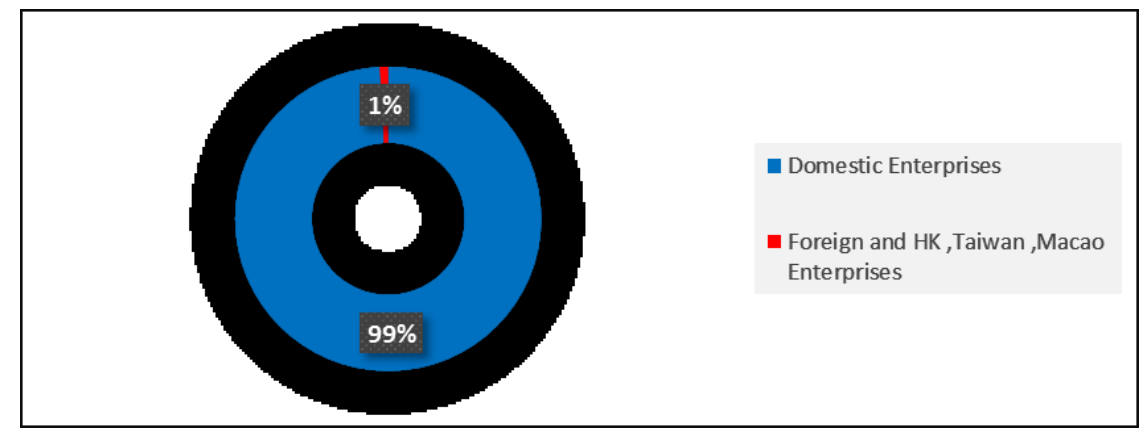

Figure 2: Number of foreign firms compared with a number of local firms 2013

(National Bureau of Statistics of China)

From the previous Figure 2, it is clear that foreign companies in the Chinese market does not exceed one percent of the total operating companies in the construction market, so it is clear that the amount of competition faced by these companies in the construction market of China is very fierce.

\subsection{Political and Legal environment:}

\section{Analysis Of China's Macro Environment:}

In order to regulate the construction market in China, Chinese government introduced a number of relevant laws and regulations, the Construction Law of the People's Republic of China came into force on 1 March 1998, In recent years, government departments are exerting effort to improve the performance effectiveness of the Chinese construction industry by formulating laws, regulations, policies and guidelines to modernize the construction market [3] , as a result of China's accession to the WTO, the opening up of China's market invites more liberal participation by foreign construction firms who were previously limited to undertake projects in this market, In fact, Investment Construction Enterprises Regulations promulgated in 2002, help to open up market access to foreign enterprises. For the first time, wholly foreign-owned construction enterprises can be legally established in China. In the Eleventh Five-Year period, the Chinese government implement 4 trillion RMB investment plan to develop the infrastructure of the urban and rural area, this provides a good political environment for construction industry. 


\subsection{Economic environment:}

China is the world's second largest economy by nominal GDP and by purchasing power parity after the United States. It is the world's fastest-growing major economy, since the economic reform started in 1978, China has become the world's fastest growing economy at an average annual rate of $9 \%$ in real terms for the past 15 years, and the rapid economic expansion has resulted in many construction activities and has created one of the largest construction market in the world. The increase in economic activity has generated, and will continue to do a heavy demand for construction for at least the next 10 years.

\subsection{Social and Cultural environment:}

China has the biggest population in the whole world with an estimated 1,430,000,000 people taken from a census in 2013[4], It has been expanding approximately by 15 million each year, Chinese culture is very complicated, For foreigners the first difficult thing when they doing construction business in china is the Chinese language, the Chinese characters are pictographs and Chinese also differs from Western languages in that it is a monosyllable language, Even after foreigners have stayed for a long time in this country and have mastered Chinese sufficiently to be able to communicate without a translator, however, they are still likely to meet obstacles when talking with Chinese people, foreign Firms may not know how to manage Chinese consultants, contractors, sub-contractors and workers, due to different cultural backgrounds between citizens of China, For successful outcomes of foreign construction firms they should understand the culture of china, and even if they do not know what the similarities between cultures of home and host country, they should at least know the differences [5].

\subsection{Technological Environment:}

China's construction technology has been continuously improving. 1986-1990 period, China construction building capacity was very limited, Complete the focus of the project was mainly in the China central television (CCTV) and power plant, electrified railway, etc. after 1990 year China completed many construction projects in different areas, such as Daya bay, qinshan nuclear power station, jinmao tower in Shanghai was very remarkable project, after that the scale of China's key project became a higher level and difficulty again like as A bird's nest can hold 91000 people, National swimming center which was the first one in the world had no experience cloud learn from it, from all these project we can see China Construction current level of technology has reached a considerable height and difficulty level, But in spite of these achievements, and these large-scale projects, the machines that are commonly used in the construction and construction production, is still relatively backward, so that China in the construction industry relies on manpower, and this is done through a lot of workers and sometimes manual mechanical equipment and the low level of advanced tools, machinery and tools are less so. In this sense given a greater opportunity to foreign companies to compete in the Chinese construction market.

In summary, based on the discussions in this section, It's necessary for foreign companies to understand external environment of china construction industry before entering that through this understanding, will give a full conception of the nature of this market from different aspects .

\section{Government Regulatory Policies On The Construction Industry}

On April 8, 2003 the Ministry of Construction issued the Relevant Administration of Qualifications in the Administration of Foreign-invested Construction Enterprises Provisions Implemented Procedures, these rules bolster the Administration of Foreign-invested Construction Enterprises Provisions (FICE Provisions) which became effective on December 1, 2002, where prior to the issuance of the FICE Provisions, foreign construction companies could only undertake construction projects in China on a project specific basis by obtaining a "foreign contractor qualification certificate" and a PRC business license. In contrast, FICEs can now engage in multiple independent projects and are not limited to one particular contract, according to the FICE Provisions, foreign investors may establish FICEs as Sino-foreign equity or cooperative joint ventures, or as wholly foreign-owned enterprises (WFOEs), FICEs can also be established through reinvestment by a foreigninvested enterprise or by way of a foreign-invested enterprise's purchase of shares in another construction enterprise, However Decree 114 from construction Regulations, is the term "foreign investment construction enterprises" refers to FICEs categories[6][7]. The wholly foreign-owned construction enterprises may undertake only a limited range of projects (Article 15) which are:

1) Construction works funded totally by foreign investment or funded by international financial organizations and awarded through international tendering.

2) Sino-foreign joint venture construction projects that are funded at least $50 \%$ by foreign investment, or other Sino-foreign joint venture construction projects that are technically difficult for a Chinese construction enterprise working independently. 
3) China invested construction projects that are technically difficult for a Chinese construction enterprise working independently, may be undertaken by Chinese and foreign construction enterprises jointly.

\section{The Main Types Of Foreign Construction Enterprise Development Strategy In The Chinese Market:}

\subsection{Corporate level strategies:}

Many foreign firms implement two or more forms of growth strategies, in order to speed up the increase in market share or sales, a strategy of an organization forms a comprehensive plan describes how the corporate achieve its objectives[8], foreign firms in china constructions industry implement two types of corporate level strategy that a business can employ:

\subsubsection{Diversification Strategy:}

Diversification strategies, become one of the good choice for foreign construction firms to increase efficiency, reduce costs and gain better control of its supply chain, Ansoff [9], who defined diversification as a developing strategy through which a company manages more than two different kinds of products or services simultaneously. Enterprises implement diversification strategy which takes the advancement of external competition and internal resources as the major considerations, construction firms have diversified into different industries, some related and others are not, the most common industries were concrete followed by real estate , the least favored form is Construction machinery and raw materials as it requires intensive capital investments .

They are three main reasons that the foreign company implement diversification strategy in china, which the first reason is the Market Power belief which assumes that as a firm becomes conglomerate, it can obtain stronger position. The second one is when the company implement diversification to uplift the status of the firm and provide protection to the financial conditions of the firm in times of fierce competition from local companies, the third reason known as the resource view encourages diversification when there are excess resources in the firm that can be elsewhere and be more productive. The foreign firms diversify strategically comes only after careful organizational analysis that the capabilities required will be available to support diversification such as financial and human resources, the benefit of diversification when foreign construction firms implement this strategy in Chinese market:

1) Diversification can recover the firm from debt capacity and improve the situation. By diversifying into other profitable businesses, which can decrease the possibility of going bankrupt by investing into different or newer industries. Within the construction sector, it is beneficial to gain economies of scale both in the short and long term, this will save resources and decrease the chances of duplicating effort.

2) Capital and Labor productivity is increased due to diversification because skills and expertise developed in one business field can be transferred to another. This is achieved by putting any idle resource and competencies into effective use, many architecture and contractors offer advisory services to other companies when engineers and project managers have no routine or work is less[10].

3) In market where taxes exist, diversified foreign firms can enjoy transferring capital from a surplus division to a deficit division unaccompanied by transaction costs.

4) Diversification allows a firm to take advantage of the strategic gap that exists in competitive environments. Such as owning a cement production facility can guarantee timely delivery of the building material to the site.

But at the same time there are some challenges that foreign companies may face when implementing this strategy, such as the foreign firms does not have the required skill and expertise to manage the other businesses in Chinese market, culture differences can result in problems or HR issues that will require time and effort to solve.

\subsubsection{Vertical Integration:}

Vertical Integration this is often choice for foreign construction firms, It involves the firm investing in its supply chain activities, many contractors acquire supplies of raw materials such as aggregates steel and iron markets, this provides the Contractors with more control over its environment and increased technological expertise and intelligence [11] .The motives lead to choosing vertical integration are grouped into four categories: 


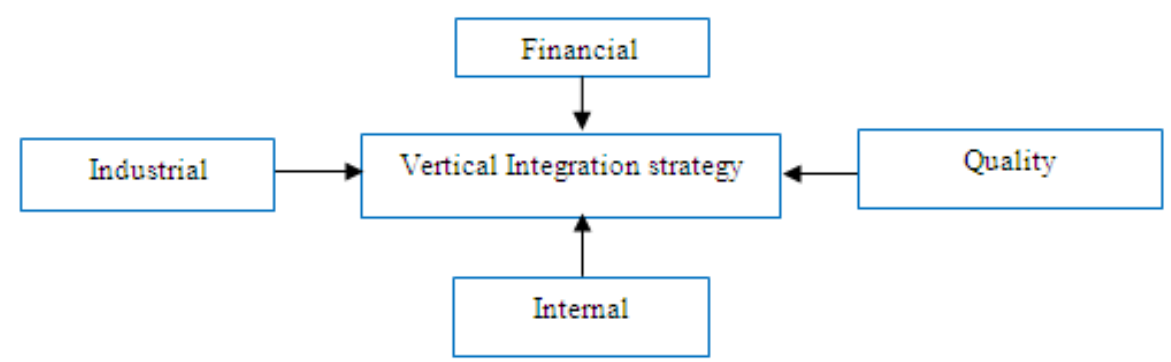

Figure 3: Categories of vertical integration strategy

1) Industrial: china industry is in a growth phase and reaping profits is fairly easy, china's construction if supplier power is weak within the industry due to competition, vertical integration is a good choice which can increase the control over the supply chain.

2) Internal Elements that are related to the internal growth of the firm are another cause to vertically integrate, in first hand tangible resources such as finance, labor and plants that are being idle, it is better to utilize them in a business line that can benefit the firm. In the second hand Intangible resources are another cause for the firm to vertically integrate, for example intellectual capital, or knowledge and information, and which when put in use by another firm can produce impressive results, and it would be more beneficial for the firm to own the whole chain.

3) Financial : financial reasons push firms to vertically integrate in order to reduce cost pressures, For example, is very common for foreign contractors in China to vertically integrate to create logistics firms, such as transportation, because it will be easier for them to control the movement of materials from one site to another with lower costs [12]

4) Quality: is concerned with the ability of the materials required to always be available on time to complete the tasks. Vertical integration allows the firm to increase its quality perspectives as it gains control over inputs, movement of materials and availability of resources.

Vertical integration have one main notable disadvantage in construction, when a firm invests in concentric diversification and vertically integrates it risks losing profits for the entire organization. For example if the demand for high rise buildings fall, the business units for cement will fall as well.

\subsection{Business level strategies:}

The cost leadership and differentiation strategies can be considered as the mode of competition, which refers to a firm's decision on the methods of developing competitive advantage (Porter, 1985)[13].

\subsubsection{Differentiation strategy:}

Differentiation is concerned with creating something that is perceived by the buyers as unique, It implies that a firm offers something unique and unmatched by its competitors and valued by the industry that enables the firm to command higher prices than industry average [14], In construction industry the differentiation strategy is directly supported by the five variables which are : Guanxi resource, project management competencies, technological and innovative capabilities, financial capabilities and reputation.

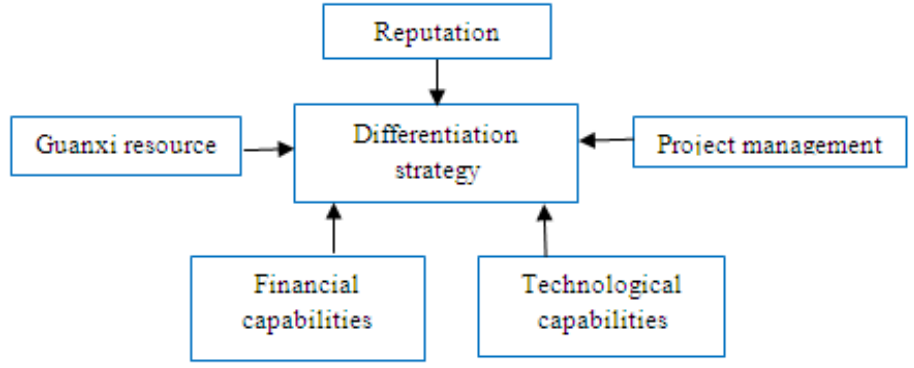

Figure 4: Variables of differentiation strategy

1) Reputation / Brand name is important resource possessed by many foreign companies to differentiate themselves from their Chinese competitors. The reputation of completing high quality projects may be circulated within network of clients in different markets, regions and industries, reputation firms is an invaluable intangible asset.

2) Guanxi (Relations) resources, clients select contractors based on their Guanxi with these contractors, where 
that Guanxi resources are one important advantage to differentiate these companies from their competitors. Guanxi resources the industrial environment of the construction industry in China has a high degree of institutional uncertainty [15] . Many projects in china, clients select contractors based on their Guanxi with these contractors.

3) Financial capabilities: this ability can be fostered by building up guanxi with financial institutions or by raising capital as publicly listed firms. Another type of financial capability that has been identified is a company's foresight in making strategic investments and project investments. Such as invest in real estate, or invest in financial institutions and some foreign companies also invest their equity directly in some projects in order to seek a return that is higher than what the conventional scope of engineering and construction works could offer.

4) High quality projects, strong project management competencies would ensure that a project is completed on time, within budget and with desirable level of quality. In most foreign construction companies, project management remains a key function.

5) Technological capabilities can contribute to the growth in market share through the provisions of new or improved products and services and the reduction in construction costs.

\subsubsection{Cost leader ship strategy:}

In cost leadership strategy, requires management to focus its attention on competing on cost, this necessitates that systems and procedures are directed totally towards controlling cost, where it is sometimes difficult to determine whether one company is indeed having a cost advantage over its competitors. It is also difficult to know whether the bidding price of a company is greater than the project cost, most of the cost controlling activities can be categorized into: Materials and equipment cost control; Manpower cost control; Subcontracting cost control; Administrative cost control, for that many foreign firms possesses a good system in controlling the cost of project management 'objective cost control' method to control these five items. According to (Yan 2004) [16] definition, 'objective cost control' simply means that an enterprise should minimize every cost activities while maximizing the objective profit. Where the cost controlling activities under the project management domain include: allocating manpower to reduce the cost according to the characteristics of different projects stages throughout the construction process; analyzing the price tendency of materials and equipment before the start of project, and maintain flexibility on allocating materials and equipment according to the projected schedule of each projects, where that the project management competencies and financial capabilities would directly support the cost leadership strategy.

\subsection{Functional-level strategies :}

A functional strategy is one that dictates the task and activities of a certain business area. Common areas where a company may implement a functional strategy marketing, finance, or the research and development departments and human resource. Here we discuss two types of strategy which foreign firms implement in Chinese construction market.

\subsubsection{Human resource strategy :}

Human resources strategy, develop and retain quality staff to work in China many foreign companies believe the Generation Y (1977-1994) years old are wielding more influences on businesses work, staff and their attitudes are the key to delivering client services, Human resource in foreign firms managed very carefully to ensure that only the best people are selected, that they are given high quality and appropriate training and development, that they are suitably rewarded to reflect their value, and their commitment to the organization is recognized, Moreover the foreign firm encourages all employees in the company to take part in develop the company and adopts the following HR strategies:

1) Introduce various incentives to encourage the employees' special contribution beyond the job description: job bonus, performance bonus, special achievement bonus.

2) By methods of sourcing, recruit professionals and graduates to make the percentage of employees with Masters and Ph.D degrees up to $20 \%$.

3) Setting up good employer working stations to carry out work exercises and develop the Team worker, this not only enhances training for the employees, but also maintains a strong network with universities, which serve as important sources of new recruits.

\subsubsection{Financial Strategy:}

The financing conditions in the Chinese construction industry are not suitable, many clients do not pay their contractors timely and fully [17]. These late payments were mainly due to the shortage of available funds for many construction projects even at the early stage of implementation. 
Therefore, to keep a project moving, a foreign construction firm would typically have to use its own funds. Thus, many foreign firms first maintain a good Guanxi with different financial institutions to improve their access to financial resources, moreover some of them invest in financial institutions to become their main shareholders, or investments in both related and unrelated industries in order to support a company's diversification strategy and build up good Guanxi with clients to reduce late payments or through this relationship may the customer give an opportunity for foreign companies to become one of project investments .

\subsection{Innovation strategy:}

Innovation strategy is that part of strategy which deals particularly with the growth of an organization through the development of new products, services, processes or business models. Where the types of innovation can be divided into process innovation and product Process Innovation is an improvement in construction methods designed to accomplish usual construction operations or to improve the efficiency of a standard operation. On the other hand, Product Innovation is an innovation that produces a qualitatively superior product. Moreover product innovation is one important advantage for creating a higher quality product [18].

- Product Innovation :

1) Innovation on Equipment's and materials design such as the structure of facilities and equipment, development of special materials, design computation and machining techniques.

2) Adding flexible modes in exploring new techniques, new products and new technologies.

3) By fully utilizing commercial software and hardware platforms, company manages to form proprietary, efficient and low-cost control systems.

- Process Innovation:

1) Continually improve on the current software and management program to elevate management efficiency and capability.

2) Improvement software innovation and construction design techniques

3) Re-engineering and Optimizing the current technical processes

\section{Analysis Of The Competitiveness Of Foreign Construction Enterprises In China:}

1) Strong project management, and better information management facilities:

There are various types of construction project management approaches such as construction $\backslash$ bidlbuild; design/build; construction management; and others. Many Chinese construction enterprises still have little experience in adopting these approaches of project management, while the foreign firms are generally knowledgeable and have experience in practicing most of these approaches. In China construction market foreign firms have the advantage of being better equipped with advanced information management facilities the Chinese government has launched an official program in 2003 to advance the information technology and management skills (MOC , 2003b)[19]. In line with this program, by 2008, those programs with special grade qualifications are expected to catch up with the information management standard owned by the world class construction firms, for example, by having their own intranet systems and getting professionals or managerial staff connected to the internet systems. The program also specifies that by 2008 those Grade A will develop their information management capacities to the level that world-class firms have already built up in 2004.

\section{2) Advanced Machine and Equipment, Higher Labor Productivity}

Compared to the Chinese construction firms, foreign firms have advantages of possessing construction machines and equipment. Comparisons of plant capacity, in terms of the value of machines per laborer, this has been shown previously when was mentioned to innovation strategy. Foreign firms can achieve higher labor productivity throw implementing HR strategy, foreign firms higher productivity is due to multiple factors, including advanced technology and equipment, more capable human resources, and efficient organization structures.

\section{3) Good cost control skill and good finance-raising ability}

Foreign firms have systems are better established and enforced. Many foreign firms have a foreign and Chinese team in charge of read all the contract, many foreign required contractors to read and stamp on every page of the contract documentation because some Chinese sign contracts without paying attention to all their legal duties and liabilities. Bye this method and differentiation strategy, cost leader ship strategy foreign firms can control the cost. Sophisticated clients may require financial support from the contractors, as was mentioned earlier, foreign companies are establishing good relationships with various financial companies and with own clients these make them have good finance-raising ability. 


\section{4) Wide international business connections:}

This strength has twofold meanings in terms of foreign contractors' marketing. First, foreign firms' international business contacts might provide business information or even directly recommend them to the potential clients (i.e. foreign investors in China). Second, Chinese clients might prefer foreign contractors if the latter could help the former' marketing outside China. For example, a Chinese industry park developer may like to engage a foreign contractor who can provide leads to attract foreign investors.

\section{Conclusion}

Economic growth in China has led to a booming construction market in various sectors. Which attract many foreign construction firms to this market, but the complex , also the intense competition and dynamic nature of the Chinese construction market, especially the differences in culture as well as in administrative and legal systems, the risks associated with these opportunities should not be under minded ,foreign construction firms face significant challenges as well, misunderstandings of differences in business operation in a different environment can lead to foreign constriction firms failures in managing projects and in pursuing business ambitions in China this led to exerted much pressure on foreign construction enterprises, Therefore, it is necessary to foreign companies to understand external environment of china construction industry before entering that through this understanding, will give a full conception of the nature of this market from different aspects. Foreign companies in china's construction market implementation certain strategies to ensure survival, a competitive advantage, and superior performance.

This paper gave a clear picture about the foreign companies in Chinese construction market and the strategies implemented by these companies to face fierce competition from local companies. Through these strategies give an opportunity for foreign companies to competitive advantage in the Chinese market, take into account as research endeavored related to these topics are very limited.

\section{References}

[1]. China.Statistical.Yearbooksa(NBSC.2012).Beijing,.China..Statistical.Publications ,Retrieved August 25, 2013,from http://www.stats.gov.cn/tjsj/ndsj/2013/indexch.htm

[2]. China National Bureau of Statistics, Department of Investment and Construction Statistics (2012), China Statistical Year Book on Construction, China Statistics Press, Beijing (in Chinese).

[3]. Zhu, H. and Dong, Yu. (2002), an analysis of the external environment for the development strategies of the Chinese construction enterprises, Research on Construction Project Management, Vol. 3 (in Chinese).

[4]. World population review 2013 :http://worldpopulationreview.com/countries/

[5]. Low, S.P. and Shi, Y.Q. (2002), An exploratory study of Hofstedes cross-cultural dimensions in construction projects, Management Decision, Vol. 40 No. 1, pp. 7-16.

[6]. China Daily,(2005). Construction Industry's WTO Commitments. Retrieved August 25, 2011 , from http://bizChina.Chinadaily.com.cn/guide/industry/industry5-03.htm

[7]. Ministry of Construction (MOC, 2002a), Regulation on administration of foreign-invested construction enterprises, Joint Ordinance of Ministry of Construction and Ministry of Foreign Trade and Economics, Beijing.

[8]. Wheelen, T.L., and Hunger, J.D. (1995), Strategic Management and Business Policy, (5th ed.) Addison Wesley, Rea ding, MA.

[9]. Ansoff, I. H.(1984), Implanting Strategic Management 2nd, New York: Prentice Hall.

[10]. Bowman, E.H. \& Helfat C.E. (2001), Does Corporate Strategy Matter? Strategic Management Journal, $22(1)$, 1 -14.

[11]. Palepu, K. (1985) ,Diversification Strategy. Profit Performance and the Entropy Measure, Strategic Management Journal 6: 239255.

[12]. Hill CWL, Hoskisson RE. (1987), Strategy and structure in the multi-product firm, Academy of Management Review 12(2): 331341.

[13]. Porter ME. (1985), Competitive Strategy: Techniques for Analyzing Industries and Competitors. Free Press: New York.

[14]. Kale, S. (1999), Competitive advantage in the construction industry: firm specific resources and strategy, PhD dissertation, Illinois Institute of Technology.

[15]. Zhu, H. and Hu, X. (2001), China's construction regulatory systems, Building

[16]. Research \& Information, Vol. 29, No. 4, pp. 265-269.

[17]. Yan, M.S., (2004), Discussion on business management in Chinese Construction Enterprises, Fujian Architecture and Construction, Vol. 89, No.4, pp.87-88

[18]. Lu, Y. J. \& Fox, P. W.(2001) ， The construction industry in China : its image, Employment prospects and,skill requirements, Sectorial Activities Program working paper, August 25, 2011.

[19]. Slaughter, S. (1998), Models of construction innovation, Journal of Construction Engineering and Management, Vol. 124, No. 2, pp. 226-231.

[20]. Ministry of Construction (MOC,2002b), Regulation on administration of foreign-invested construction engineering design enterprises, Joint Ordinance of Ministry of Construction and Ministry of Foreign Trade and Economics, Beijing.

[21]. China Construction Industry Overview( 2011), Published by: Turkish Industry \& Business Association, August 2011 .

[22]. Bajaj, D., \& Zhang, R. (2003), Managing construction industry development in China, The AACE International Transactions, AACE Annual Conference 2003, Morgantown, WV. 